\title{
Trial and intertrial durations in appetitive conditioning in rats
}

\author{
PETER C. HOLLAND \\ Duke University, Durham, North Carolina
}

\begin{abstract}
The effects of trial $(T)$ and intertrial $(I)$ durations were examined in two Pavlovian conditioning experiments with rats, in which a noise conditioned stimulus (CS) was paired with food delivery. In Experiment 1, $T$ was either 10 or $20 \mathrm{sec}$, and $I$ ranged from 15 to $960 \mathrm{sec}$, in separate groups of rats. The acquisition rate and final level of conditioned responding showed ratio invariance: They were better predicted by the $I / T$ ratio than by $I$ or $T$ alone. In Experiment 2, the $I / T$ ratio was 6.0 in all the groups, and $T$ was $20,40,80$, or $160 \mathrm{sec}$. Ratio invariance was not observed: Despite the common $I / T$ ratio, the rate of acquisition, final level of conditioned responding, and the ability of the CS to block conditioning of another stimulus differed among the groups. At the same time, the temporal distribution of conditioned responding within $T$ was similar in all the groups throughout conditioning and extinction and showed superpositioning when normalized across $T$. Many but not all aspects of the data were consistent with scalar timing theory.
\end{abstract}

Time has long been assumed to be a key variable in associative learning. Not only has temporal contiguity between events been viewed as a critical condition for the occurrence of learning, but also temporal information has been posited to be an important aspect of the content of learning (Gallistel, 1990; Gibbon \& Church, 1990; Miller \& Barnet, 1993; Savastano \& Miller, 1998). Most early research concentrated on single temporal parameters and absolute effects of time. For example, exploration of new conditioning preparations often began with the determination of interstimulus interval (ISI) functions (Holland, 1980; Kamin, 1965; Ross, 1961; Schneiderman \& Gormezano, 1964) that related the amount or rate of learning to the time between the onsets of the conditioned stimulus (CS) and the unconditioned stimulus (US). Likewise, trial-spacing effects figured prominently in early theories of interference and memory for events in conditioning episodes (Capaldi, 1967).

It is now clear that the effects of one temporal variable can be modulated by other temporal variables. Evidence from a variety of conditioning paradigms suggests that conditioned responding often involves sensitivity to the ratio of two time intervals, the average interval between trials (usually termed the cycle or intertrial duration, I, in this literature) and some within-trial interval, such as the time between CS and US presentation (usually termed

This research was supported in part by grants from the National Science Foundation and the National Institute of Mental Health. I thank John Chen and James Wallace for technical assistance in Experiment 1 and $\mathrm{R}$. Church and W. Meck for helpful comments on an earlier version of this paper. James Wallace's participation was part of a mentorship program at the North Carolina School of Science and Mathematics. Correspondence concerning this article should be addressed to $\mathrm{P}$. C. Holland, Department of Psychology: Experimental, Duke University, Box 90086, Durham, NC 27708-0086 (e-mail: pch@duke.edu). the trial duration, $T)$. For example, Gibbon, Baldock, Locurto, Gold, and Terrace (1977) found that the number of trials for pigeons to reach an acquisition criterion in autoshaped keypecking procedures was best described by the $I / T$ ratio across a broad range of absolute time intervals. Similar ratio effects have been observed in discrimination tasks. Williams (1998) trained rats in a conditional discrimination in which two cues signaled which of two levers would be the correct (reinforced) lever when they were subsequently inserted into the chamber. Discrimination performance was better when the delays between cue presentation and lever insertion were short and when $I$ was long, but the delay effects were more evident with short Is. Similarly, Spetch and Rusak (1992) found that variations in sample delays in delayed matching-tosample (DMTS) procedures had more effect with short Is than with lengthy Is. Roberts and Kraemer (1982) further found that pigeons' DMTS performance was better described by the ratio of $I$ and the delay interval than by either of those absolute time intervals alone.

Holland (1995) and Holland and Morell (1996) found that rats' acquisition of operant serial feature-positive and serial feature-negative discriminations was affected both by the interval between the feature and the target and by $I$. Consistent with Roberts and Kraemer's (1982) results, the ratio of $I$ and the feature-target interval was the best predictor of discrimination acquisition. However, in both Holland's (1995) and Holland and Morell's studies, the differences in discrimination learning across the training conditions reflected differential losses in responding on nonreinforced trials, rather than differences in responding on reinforced trials. Indeed, even in simple conditioning of either the feature $\rightarrow$ target compound or the target-alone cue, no effects of $I$ were observed. Although Holland (1995) and Holland and Morell pointed out that their studies may not have provided an adequate opportun- 
ity to examine initial learning - acquisition was very rapid in all conditions, and the rats had been previously trained to perform the same operant in the presence of another auditory cue with a common $I$ value in all the groupsthey also raised the possibility that appetitive conditioning of rats is simply not sensitive to the $I / T$ ratio.

Recent evidence denies this possibility. In several experiments that used Pavlovian conditioning procedures, Lattal (1999) found that rats' acquisition of food cup entry responding was more rapid with larger $I / T$ ratios. Nevertheless, Lattal found that acquisition rates were also affected by the absolute $I$ and $T$ values; with any given $I / T$ ratio, shorter values of $T$ generated more rapid learning.

The experiments reported in this article replicated and extended Lattal's (1999) findings in several ways. First, in Experiment 1, the effects of a range of $I / T$ ratios were examined systematically within a single experiment. As in Lattal's studies, the $I / T$ ratio was the best predictor of acquisition rate and final level of performance. Second, in Experiment 2, the generality of this ratio effect was explored by comparing conditioning over a broad range of $I$ and $T$ values, while holding the $I / T$ ratio constant. Third, the contributions of $I / T$ ratio to learning and performance were disentangled by giving performance tests with common $I / T$ ratios after training rats with different $I / T$ ratios and by testing rats after extensive nonreinforced exposure to the context. Lattal tested rats with several combinations of $I$ and $T$ after training with a single combination and found test behavior to reflect the training parameters, regardless of the values used in testing. Similarly, Lattal found that $I / T$ ratio effects were mostly maintained after extensive exposure to the experimental context in the absence of the food US, which reduced the intertrial food rate to zero in all conditions. Fourth, the effects of these temporal variables on an indirect measure of associative strength, the ability of a CS to block subsequent acquisition of conditioning to another stimulus, were examined. Fifth, the effects of these variables on the temporal distribution of responding within $T$ were described. Finally, a number of measures of conditioned responding were recorded, including the duration, rate, and latency of food cup entries. Other studies from this laboratory (e.g., Holland, Lamoureux, Han, \& Gallagher, 1999) suggest that these measures may not always be well correlated.

\section{EXPERIMENT 1}

In Experiment 1, the rats were first given Pavlovian pairings of a noise CS and a food pellet US. For six groups of rats, $T$ was $10 \mathrm{sec}$, and for six groups $T$ was $20 \mathrm{sec}$. Previous studies with long $(480-\mathrm{sec}) I$ values showed faster acquisition with $10-\mathrm{sec}$ than with $20-\mathrm{sec} T \mathrm{~s}$. The values of $I$ used were chosen to produce $I / T$ ratios of $1.5,3.0$, $6.0,12.0,24.0$, and 48.0 for each value of $T$. Thus, across a range of $I$ values, the effects of $T$ could be considered between groups trained with the same $I \mathrm{~s}$ or between groups trained with the same $I / T$ ratios.
In this experiment, $T$ signified both the duration of the noise CS and the interval between its onset and the delivery of the food US. Although this confounding of ISI and CS duration makes it impossible to separately assess the effects of each of those variables, it is consistent with the procedures of all previous investigations of $I / T$ ratio effects and with Gibbon and Balsam's (1981) theoretical analysis of those effects.

As in most conditioning studies, in the acquisition phase of Experiment 1, the conditions of learning itself and the conditions under which that learning is assessed were necessarily confounded (see Lattal, 1999, and Rescorla \& Holland, 1976, for discussions of the implications of that confound). Differences in behavior among groups trained with different $I / T$ ratios might reflect differences in their learning, or they might reflect differences in how learning is expressed at different $I / T$ ratios. This learning performance distinction is critical to theoretical accounts for $I / T$. For example, Gibbon and Balsam (1981) suggested that $I / T$ ratio effects are performance effects rather than acquisition effects. Within their interpretation, the associative strength of a CS is determined solely by $T$, but performance of conditioned responses during $T$ is a function of both that strength and the average strength during $I$. By contrast, other attempts to account for $I$ and $I / T$ ratio effects (e.g., Rescorla \& Wagner, 1972; Wagner, 1981) have attributed them to differences in learning about the CSs, appealing, for example, to competition between conditioning of the context and that of the explicit CS.

To distinguish between the effects of $I$ and the $I / T$ ratio on learning from their effects on performance, all of the rats were tested with both 60 -sec and $240-\mathrm{sec} I \mathrm{~s}$ at the end of training. Differences in responding observed among the groups when they are tested under common conditions are likely to reflect differences in underlying learning among those groups.

\section{Method}

Subjects. Ninety-six experimentally naive male CD-strain rats (Charles River Breeding Laboratories, Raleigh, NC), 100 days old at the beginning of the experiment, served as subjects. The rats were individually housed in individual stainless steel cages in a vivarium that was maintained at $21^{\circ} \mathrm{C}$, with the lights on from 6:00 a.m. to 8:00 p.m. All the experimental sessions were carried out during the light portion of the cycle, between 7:00 a.m. and 2:00 p.m. The rats were maintained at $85 \%$ of their ad-lib weights by limiting their access to food; water was always available.

Apparatus. The apparatus consisted of eight individual chambers $(22.9 \times 20.3 \times 20.3 \mathrm{~cm})$ with aluminum front and back walls, clear acrylic sides and top, and a grid floor $(0.48-\mathrm{cm}$ stainless steel rods spaced $1.9 \mathrm{~cm}$ apart). A dimly illuminated food cup was recessed in the center of the front wall, with an infrared photocell flush with the wall. Computer equipment sampled the photocells at a rate of approximately $1 \mathrm{kHz}$. A 6-W jeweled lamp was mounted $10 \mathrm{~cm}$ above the recessed food cup; this lamp was not used in Experiment 1. Each experimental chamber was enclosed in a soundresistant shell with an acrylic window for viewing the rats. A speaker, used to present the auditory CS, was mounted on the inside wall of the shell, $10 \mathrm{~cm}$ above the experimental chamber and even with the end wall that contained the food cup. Ventilation fans provided masking noise $(70 \mathrm{~dB})$, and a $6-\mathrm{W}, 110-\mathrm{V}$ lamp (operated at 
$75 \mathrm{~V}$ ) behind a red lens opposite the houselight provided continuous dim background illumination. Two low-light television cameras were mounted $2.1 \mathrm{~m}$ from the experimental chambers so each could include four chambers in its field of view. Videocassette recorders were programmed to record behaviors that occurred during the 10 sec intervals before, during, and after CS presentations.

Procedure. Initially, all the rats were trained to eat from the recessed food cup. In a single 32-min session, there were 16 presentations of the event used as the US throughout this experiment, two $45-\mathrm{mg}$ food pellets (PJ Noyes) delivered $0.5 \mathrm{sec}$ apart, on a variable-time (VT) 2-min, equal probability schedule. Next, all the rats received eight pairings of an $80-\mathrm{dB}$ (A scale) white noise CS with the two-pellet food US in each of 16 daily conditioning sessions. Each group of rats received a single combination of $T$ (duration of the noise CS trial) and $I$ (time between trial onsets, equivalent to the interfood interval), as specified (in seconds) by the group name, $T-I$ : $10-15,10-30,10-60,10-120,10-240,10-480,20-30,20-60$, $20-120,20-240,20-480$, and $20-960$. In each group, $T$ was constant. By contrast, in each group the $I$ s were variable, with the specified arithmetic mean; the values of $I$ ranged from 0.5 to 1.5 times the mean, rectangularly distributed. Note that with this schedule, the average time to food delivery is not constant throughout a session. The session lengths were eight times the mean $I$ values and so varied from 2 to $128 \mathrm{~min}$ across the groups.

Finally, the rats received two test sessions designed to disentangle learning and performance effects. In each of these sessions, all the groups were tested with a single $I$ value. Each session comprised eight reinforced noise trials, with the original training values of $T$ in each group. For half of the rats in each group, the first session was $8 \mathrm{~min}$ long, with $I=60 \mathrm{sec}$, and the second session was $32 \mathrm{~min}$ long, with $I=240 \mathrm{sec}$. The remaining rats received those two sessions in the opposite order

Data presentation. The primary response measure was the percentage of time during a specified interval that the photocell in the food cup was activated. This measure is reported for the 10 -sec preCS period, the entire period during the 10 -sec noise CSs, and the last 10 -sec period of the $20-\mathrm{sec}$ noise CSs. Note that because each interval was $10 \mathrm{sec}$, the percentage measure is easily converted to an absolute measure of time in the food cup. The last 10-sec interval of the 20 -sec CSs was selected to provide a comparable-length sampling interval with identical relation to the time of US delivery in both ISI conditions and to make comparisons with the results of Experiment 2 simpler. The choice of measurement interval is discussed further in the General Discussion section.

In addition, the rate of food cup entry and the latency to the first food cup entry after CS onset were recorded. To further reduce withingroup variance of the time in food cup and rate of food cup entry, the primary index of conditioning reported was an elevation score, calculated by subtracting responding during the pre-CS period from that during the final $10 \mathrm{sec}$ of the CS interval. However, because in some cases pre-CS responding differed among the groups, responding during the CS and during the pre-CS intervals are also presented.

Finally, these automated measures were supplemented by observations from the videotapes, made using the methods described by Holland (1977). The observational data are not presented in detail, because their patterns were similar to those of the photocell data for percentage of time in the food cup.

\section{Results}

Acquisition: Time in food cup measure. Both the rate of acquisition of conditioned responding and final performance were linearly related to the $I / T$ ratio. There was no effect of $T$ alone when responding with the 10sec and 20-sec CSs was compared across groups trained with equal $I / T$ ratios. However, when compared across groups trained with equal $I s$, responding was greater with the $10-\sec T$ than with the $20-\sec T$.

Figure 1 shows the mean percentage of time the rats spent in the food cup during the last $10 \mathrm{sec}$ of the CS periods and the $10-\mathrm{sec}$ pre-CS periods and the mean elevation scores over the course of the conditioning phase. Separate $T \times I / T$ ratio $\times$ session blocks analyses of variance (ANOVAs) for the elevation and during-CS measures (respectively) each showed reliable effects of $I / T$ ratio $\left[F_{\mathrm{s}}(5,84)=26.49\right.$ and $\left.13.25, p \mathrm{~s}<.01\right]$ and session blocks $[F \mathrm{~s}(7,588)=72.96$ and $184.92, p \mathrm{~s}<.01]$ and significant $I / T$ ratio $\times$ session blocks interactions $\left[F_{\mathrm{s}}(35,588)=6.28\right.$ and $3.68, p \mathrm{~s}<.01]$. For the elevation measure, there was no reliable effect of $T$ or any of its interactions $(F \mathrm{~s}<1)$, but the three-way interaction was reliable for the duringCS measure $[F(35.588)=1.79, p<.01]$.

Both measures were then subjected to analyses of trend across $I / T$ ratios, with weights that reflected the equal intervals among those ratios when plotted on a log scale (as in Figure 2). Overall conditioned responding in the acquisition phase was linearly related to $I / T$ ratio. The linear trend of $I / T$ ratio was reliable for both the elevation and the during-CS measures $[F \mathrm{~s}(1,84)=126.91$ and $61.17, p \mathrm{~s}<.01]$, and no higher order trends were reliable $(F \mathrm{~s}<2.63, p \mathrm{~s} \geq .10)$. Furthermore, the rate of acquisition of responding was also linearly related to $I / T$ ratio. A partition of the $I / T$ ratio $\times$ session blocks interaction showed that the linear increase in responding that occurred over sessions was itself linearly related to $I / T$ interval with both measures $[F \mathrm{~s}(1,84)=95.64$ and 28.23 , $p \mathrm{~s}<.01]$. No other polynomial contrasts of the $I / T$ ratio $\times$ session blocks interaction were reliable $(p s>.10)$.

Pre-CS responding also differed among the groups; in general, greater responding was observed in the groups with the smallest $I / T$ ratios. An ANOVA showed reliable effects of $I / T$ ratio $[F(5,84)=4.95, p<.01]$ and session blocks $[F(7,588)=3.95, p<.01]$, but not of $T[F(1,84)=$ $1.31, p=.25]$. Session blocks interacted significantly with each of the other factors $(F \mathrm{~s}>2.97, p \mathrm{~s}<.01)$. Post hoc comparisons of the overall responding of individual groups (Duncan test) showed only that pre-CS responding was greater in Group 10-15 than in any other group ( $p$ s < .05 ); no other comparisons were reliable ( $p \mathrm{~s}>.10)$. It is important to recognize that these differences in pre-CS responding were not crucial to the observation of the effects of the $I / T$ ratio on conditioned responding just described: those effects were qualitatively similar whether pre-CS responding was compensated for (elevation scores) or not (during-CS responding).

Figure 2 shows a summary of the elevation scores for each group, collapsed across the entire conditioning phase and plotted as a function of both the $I / T$ ratio (left panel) and $I$ alone (right panel). Clearly, when comparing across groups trained with the same $I / T$ ratio, $T$ alone had no effect, over all the groups or at any individual $I / T$ ratio (statistics given previously). Indeed, a stepwise linear regression analysis of these scores, with $I / T$ ratio, $I$, and $T$ as independent variables, showed the $I / T$ ratio to be 

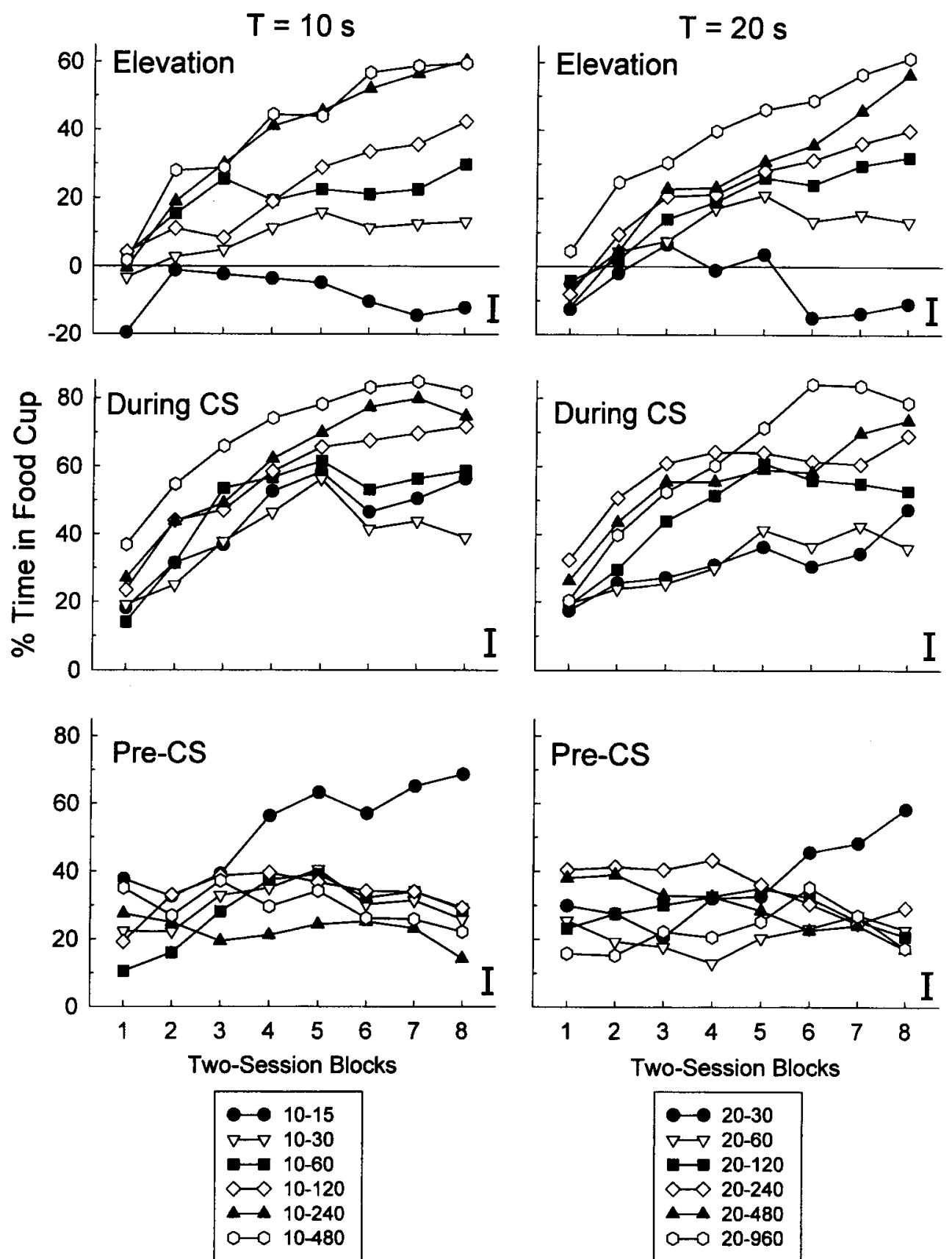

Figure 1. Acquisition of conditioned responding over sessions in Experiment 1. The left panels show responding in groups trained with 10-sec trial durations $(T)$, and the right panels show responding in groups trained with $T=20 \mathrm{sec}$. The top panels show elevation scores, calculated by subtracting responding during the 10-sec period immediately prior to conditioned stimulus (CS) presentation (bottom panels, Pre-CS) from responding during the last 10 sec of the CS (middle panels, During CS). The first number in each group designation in the legends indicates $T$, and the second number signifies the intertrial duration, both in seconds. The error bars in each panel show two times the pooled standard error of the between-groups means.

the only significant contributor to performance $[r=.66$; $F(1,94)=71.36]$. The best two- and three-variable regression models $(r \mathrm{~s}=.66$ ) were no better than the onevariable model.

Nevertheless, $T$ was important when groups trained with the same value of $I$ were compared (right panel of
Figure 2). An $I \times T \times$ session blocks ANOVA of the elevation scores of the 10 groups for which $I$ could be matched (Groups 10-15 and 20-960 were excluded) showed a reliable effect of $T[F(1,70)=15.16, p<.01]$, as well as of $I[F(4,70)=14.74, p<.01]$. The $I \times T$ interaction was not reliable $(F<1)$. Individual post hoc 

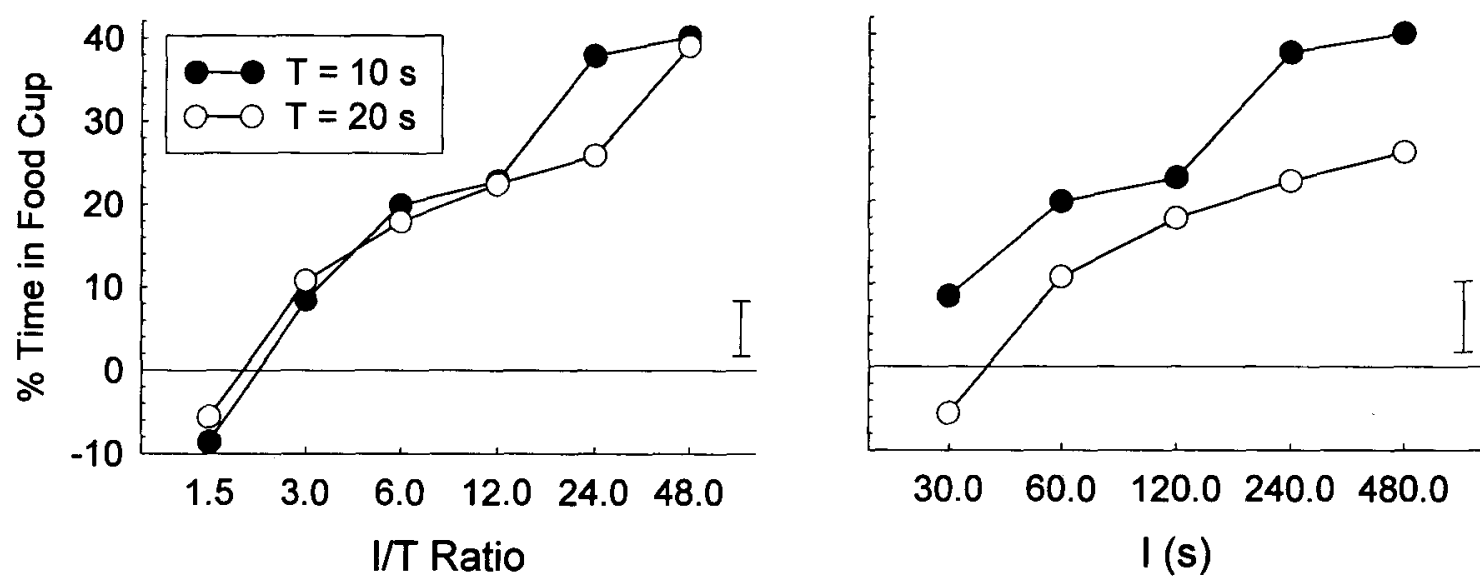

Figure 2. Summary of acquisition performance in Experiment 1. The left panel shows the performance of all 12 groups, plotted as a function of the ratio of the intertrial duration $(I)$ and the trial duration $(T)$, on a $\log$ scale. The right panel shows performance of the 10 groups trained with common $I$, plotted as a function of $I$ on a $\log$ scale. The response measure shown is the elevation score, calculated by subtracting responding during the 10 -sec period immediately prior to conditioned stimulus (CS) presentation from responding during the last 10 sec of the CS. The error bars in each panel show two times the pooled standard error of the between-groups means.

comparisons (Duncan test) showed reliably greater responding with the $10-\sec T$ than with the 20 -sec $T$ at $30-$ sec, $240-\mathrm{sec}$, and $480-\sec I \mathrm{~s}(p \mathrm{~s}<.05)$.

Acquisition: Food cup entry rate and latency to first cup entry. Each of these measures was also sensitive to the $I / T$ ratio, showing both greater conditioning with larger $I / T$ ratios and ratio invariance-that is, no effect of $T$ alone, when compared at equal $I / T$ ratios. However, the acquisition patterns of these measures differed from that of the measure of the percentage of time in the food cup. Unlike the latter measure, which showed maximum sensitivity to the $I / T$ ratio late in training, cup entry rates and latencies were most sensitive to $I / T$ ratio early in training. Tables 1 and 2 show cup entry rates and the latencies to the first cup entry after CS presentations over the first four sessions and over the last four sessions, respectively.

First, consider responding early in training (Table 1). Separate $T \times I / T$ ratio ANOVAs of the latencies to first cup entry after CS onset, rate elevation scores, and during$C S$ rates each showed a reliable effect of $I / T$ ratio $\left[F_{\mathrm{s}}(5,84)=13.81,23.57\right.$, and 7.46 , respectively, $p \mathrm{~s}<$ $.01]$ but no effect of $T$ alone ( $p s>.10$ ). As with the measure of the percentage of time in the food cup, the increasing linear trends across $I / T$ ratio were reliable for all three measures $[F \mathrm{~s}(1,84)=65.76,116.12$, and 34.95 , $p s<.01]$, and no other polynomial contrasts were significant $(p s>.10)$. By contrast, pre-CS cup entry rates were inversely related to $I / T$ ratio; the effect of $I / T$ ratio was reliable $[F(5,84)=6.78, p<.01]$, as was the decreasing linear trend across that variable $[F(1,84)=31.90$, $p<.01]$.

Neither the latency nor the rate of food cup entry during the CS maintained its sensitivity to $I / T$ ratio. ANOVAs of responding over the last four acquisition sessions
(Table 2) showed no reliable effect of $I / T$ ratio for either of those measures $(F \mathbf{S}<1)$. By contrast, the inverse relation between $I / T$ ratio and pre-CS food cup entry rates was maintained; the effect of $I / T$ ratio was reliable $[F(5,84)=27.54, p<.01]$, as was the decreasing linear trend across that variable $[F(1,84)=133.47, p<.01]$. Not surprisingly, the rate elevation scores were also sensitive to $I / T$ ratio in the last four sessions $[I / T$ ratio, $F(5,84)=17.35$; linear trend, $F(1,84)=86.27, p$ s $<$ $.01]$, but given the lack of $I / T$ ratio effects on cup entry rates during the $\mathrm{CS}$, that sensitivity is more readily attributable to the differences in pre-CS responding.

Table 1

Elevation in Cup Entry Rate and Latency to the First Food Cup Entry During Conditioned Stimuli (CSs) in the First Four Sessions of the Acquisition Phase of Experiment 1

\begin{tabular}{lcccc}
\hline Group & Latency & Elevation & Pre-CS Rate & During-CS Rate \\
\hline $10-15$ & 3.95 & -1.3 & 14.5 & 13.2 \\
$10-30$ & 3.84 & 1.7 & 12.2 & 13.9 \\
$10-60$ & 3.00 & 6.9 & 9.8 & 16.7 \\
$10-120$ & 2.50 & 9.5 & 8.6 & 18.1 \\
$10-240$ & 2.57 & 15.9 & 8.3 & 24.2 \\
$10-480$ & 1.36 & 22.0 & 5.9 & 27.9 \\
$20-30$ & 4.64 & -4.2 & 16.0 & 11.8 \\
$20-60$ & 2.90 & 4.2 & 11.3 & 15.5 \\
$20-120$ & 2.62 & 3.7 & 10.4 & 14.1 \\
$20-240$ & 1.75 & 11.0 & 8.3 & 19.3 \\
$20-480$ & 1.65 & 18.5 & 7.1 & 25.6 \\
$20-960$ & 1.50 & 18.0 & 6.7 & 24.7 \\
$S E M$ & 0.32 & 0.7 & 1.0 & 1.2 \\
\hline
\end{tabular}

Note-The first number in each group designation indicates the trial duration, and the second number indicates the intertrial duration, both in seconds. Latency values are in seconds, and rate values are in cup entries/minute. Elevation scores were calculated by subtracting the rate of cup entry in the $10 \mathrm{sec}$ prior to each CS presentation from the entry rate during the final $10 \mathrm{sec}$ of the interstimulus interval. $S E M=$ pooled standard error of the means. 
Table 2

Elevation in Cup Entry Rate and Latency to the First Food Cup Entry During Conditioned Stimuli (CSs) in the Last Four Sessions of the Acquisition Phase of Experiment 1

\begin{tabular}{lcccc}
\hline Group & Latency & Elevation & Pre-CS Rate & During-CS Rate \\
\hline $10-15$ & 1.11 & -1.0 & 22.5 & 21.5 \\
$10-30$ & 1.11 & 8.7 & 18.0 & 26.7 \\
$10-60$ & 0.88 & 10.4 & 18.3 & 28.7 \\
$10-120$ & 0.98 & 18.8 & 10.9 & 29.7 \\
$10-240$ & 0.78 & 24.1 & 6.3 & 30.4 \\
$10-480$ & 0.53 & 26.0 & 4.3 & 30.3 \\
$20-30$ & 2.17 & 6.3 & 16.1 & 22.4 \\
$20-60$ & 1.88 & 8.2 & 17.7 & 25.9 \\
$20-120$ & 1.47 & 14.5 & 11.8 & 26.3 \\
$20-240$ & 1.46 & 15.3 & 8.1 & 23.4 \\
$20-480$ & 2.40 & 20.9 & 4.6 & 25.5 \\
$20-960$ & 1.40 & 25.0 & 3.4 & 28.4 \\
$S E M$ & 0.45 & 1.2 & 0.7 & 1.5 \\
\hline
\end{tabular}

Note-The first number in each group designation indicates the trial duration, and the second number indicates the intertrial duration, both in seconds. Latency values are in seconds, and rate values are in cup entries/minute. Elevation scores were calculated by subtracting the rate of cup entry in the $10 \mathrm{sec}$ prior to each CS presentation from the entry rate during the final $10 \mathrm{sec}$ of the interstimulus interval. $S E M=$ pooled standard error of the means.

Test: Time in food cup. The effects of the $I / T$ ratio on the percentages of time spent in the food cup observed in the acquisition sessions persisted during the test sessions, in which all the rats were tested with both $60-\mathrm{sec}$ and $240-\mathrm{sec}$ Is. Figure 3 shows the elevation in percentage time spent in the food cup in the test sessions. Because of a malfunction in one of the test chambers, the data from 14 rats had to be discarded ( 1 in each of 10 groups and 2 in Groups $10-30$ and $10-60)$. A $T \times$ training $I / T$ ratio $\times$ test $I$ ANOVA showed a reliable effect of the training $I / T$ ratio $[F(5,70)=7.30, p<.01]$ but no effect of any of the other variables or their interactions $(F \mathbf{S}<1)$.

As was observed at the end of acquisition, the groups did not differ in their performance on the other response measures during the test sessions (data not shown).

\section{Discussion}

With the measure of time in the food cup, the rate of acquisition and overall performance were best predicted by the $I / T$ ratio. $T$ had no effect when compared in groups trained with the same $I / T$ ratios. Although the range of $T \mathrm{~s}$ examined ( 10 and $20 \mathrm{sec}$ ) was limited, those two values showed clear $T$ effects when assessed in groups with a common value of $I$. Note that the linear relation of $\log$ $I / T$ ratio portrayed in the left panel of Figure 2 (responding showed a constant increment for each doubling of $I$ ) guarantees the additive effect of $T$ across different values of $I$, an intriguing quantitative aspect of these data.

In any event, the $I / T$ ratio provided more information than $I$ alone, extending the basic findings of Lattal (1999) and Gibbon et al. (1977). Like Gibbon et al.'s results, but unlike Lattal's, in Experiment 1, conditioning was invariant across $T$ values within $I / T$ ratio. Indeed, despite the limited range of $T \mathrm{~s}$ examined, in some respects these findings may be construed as more robust than
Gibbon et al.'s. First, Gibbon et al. found $I / T$ ratio invariance only for a measure of acquisition, the number of trials needed to meet a response criterion or threshold. Unlike in the present study, in their experiments, sustained responding did not show this same sensitivity (see also Brown \& Hemmes, 1997). Second, Gibbon et al. found no effects of $I / T$ ratio on another common measure of conditioning strength, the latency to respond to the CS, which showed sensitivity to the $I / T$ ratio early in training in this experiment.

Not surprisingly, the groups with the highest rates of food delivery (shortest Is) spent greater percentages of the pre-CS intervals in the food cup. However, with this measure, pre-CS responding was not a critical determinant of the $I / T$ ratio effect, which was observed not only with the elevation scores but also with responding during the CSs alone. Furthermore, apart from those groups with the shortest Is, the time spent in the food cup during the pre-CS period was not systematically related to food delivery rate.

By contrast, throughout acquisition, the rate of food cup entry during the pre-CS periods was directly related to food delivery rate, increasing linearly as $I$ decreased. Also unlike the time in food cup measure, food cup entry rate during the CS was sensitive to the $I / T$ ratio only during early stages of training. These differences in response measures deserve comment. First, it is worth comparing the rate data reported in the present experiment with those of Lattal (1999), who reported only food cup entry rate. As in the present experiment, Lattal also found that pre-

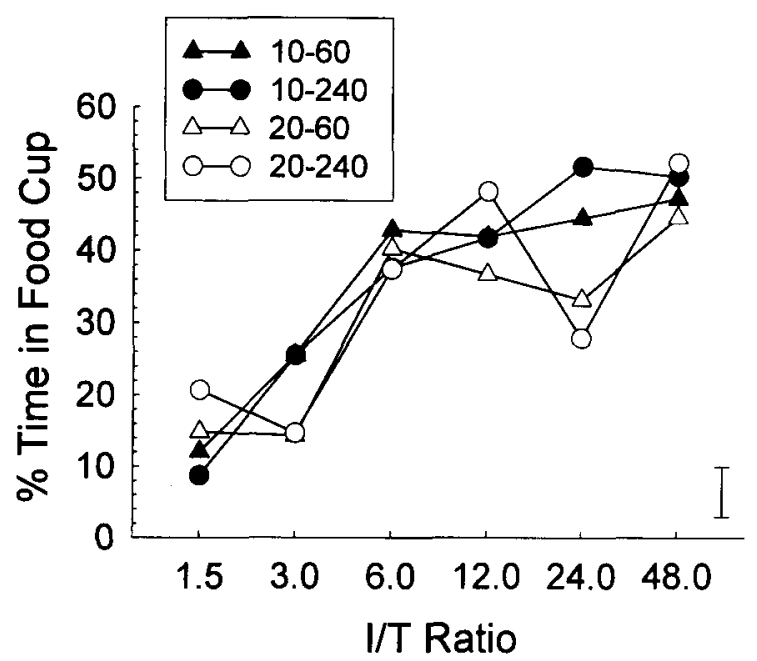

Figure 3. Performance in the test phase of Experiment 1, plotted as a function of the ratio of the intertrial duration $(I)$ and the trial duration $(T)$ used in training in each group, on a log scale. In the legend, the first number refers to the $T$ (in seconds) used in both the training and the test phases, and the second number signifies the $I$ (in seconds) used in the test phase. The response measure shown is the elevation score, calculated by subtracting responding during the 10 -sec period immediately prior to conditioned stimulus (CS) presentation from responding during the last $10 \mathrm{sec}$ of the CS. The error bar shows two times the pooled standard error of the between-groups means. 
CS food cup entry rate was often an important contributor to $I / T$ ratio effects, declining with longer values of $I$. Nevertheless, Lattal showed direct effects of the $I / T$ ratio on food cup entry rate during the CS throughout training and testing. It is notable that Lattal's studies used only four sessions of training, and so his data are perhaps more appropriately compared with our early-acquisition data (Table 1).

Second, observations of the videotapes showed that in the pre-CS periods, the rats tended to emit brief-duration entries into the recessed food cup, whereas during CS presentations, they tended to keep their heads in the food cup longer, especially as training proceeded. A general point is that the form of conditioned behavior controlled by the conditioning context alone (or the prior or anticipated delivery of food) may differ from that controlled by a discrete $\mathrm{CS}$ and that various measures of conditioning during such a CS may interact differently with behavior controlled by events other than that CS. For example, in autoshaping, keypecking is controlled by discrete visual CSs, but not by contextual cues, which tend to control less directed activity (Balsam \& Schwartz, 1981; Grau \& Rescorla, 1984; Killeen, 1975).

The pattern of pre-CS food cup entry rates across groups observed in this experiment might reflect sustained differences in responding in the absence of CSs throughout the sessions or cyclic increases as the average expected time of the next CS draws near (recall that the Is were variable). Because response timing is likely to be more accurate the shorter the $I$ (Gibbon, 1977), pre-CS responding might be especially high with shorter Is. Likewise, groups with shorter Is also had shorter sessions; thus, any tendency to explore the food cup when first placed in the chamber might contribute more to pre-CS responding in groups with short Is. Unfortunately, responding was not recorded, except during pre-CS and CS periods.

Finally, consistent with Lattal's (1999) data, the results of the test sessions indicate that the $I / T$ ratio effects observed in acquisition reflected differences in learning, not just performance. Test behavior of the rats in the various groups was indicative of the $I$ value with which they were trained, regardless of the value of $I$ used in testing. Thus, the effects observed in acquisition were unlikely to be due to short-term factors, such as differential suppression of responding during a trial as a result of food delivery on the preceding trial. Likewise, these test data are inconsistent with accounts for $I / T$ ratio effects that emphasize comparison of current food rates or expectancies during the trial and intertrial periods at the time of action (e.g., Gibbon \& Balsam, 1981), unless it were additionally claimed that the calculations of intertrial food rate or associative strength exhibited substantial inertia. Although for a number of reasons, Gibbon and Balsam argued that these calculations were adjusted rapidly, the lack of any obvious adjustment in responding in the test sessions when $I$ was altered from the training value is consistent with Spetch and Rusak's (1992) view that reference memory for $I$ is stable. This issue is considered further in Experiment 2.

\section{EXPERIMENT 2}

Experiment 2 tested the generality of Experiment 1's findings of ratio invariance by examining the effects of variations in $T$ and $I$, with a single value of the $I / T$ ratio (6). The $T$ s were extended upward from those used in $\mathrm{Ex}$ periment 1; four groups of rats received training with noise CSs with $T \mathrm{~s}$ of $20,40,80$, or $160 \mathrm{sec}$. If only the $I / T$ ratio is important for conditioning, the performance of all four groups should be indistinguishable. Differences among the groups would indicate roles for $I, T$, or both individually, beyond that of the $I / T$ ratio alone.

The use of extended $T$ s encouraged the display of more temporally organized behavior than was observed in Experiment 1 . In a variety of conditioning preparations, the level of conditioned responding peaks near the normal time of US delivery, indicating that associative learning involves the coding of temporal as well as predictive relations (see Savastano \& Miller, 1998, for a review). Furthermore, the temporal distribution of responding within $T$ often shows scalar properties - that is, when responding acquired with different $T \mathrm{~s}$ is normalized proportionally to $T$, the resultant distributions are nearly identical (superpositioning). For example, Brown and Hemmes (1997) measured pigeons' proximity to the source of a food US during visual CSs presented with $T \mathrm{~s}$ of 18,24 , or $60 \mathrm{sec}$. When responding in each one-sixth of $T$ was expressed as a fraction of the total responding during $T$, the distributions were indistinguishable across the three values of $T$. Similar superpositioning effects have long been noted in the control of operant responding under fixed-interval schedules (Catania, 1970). In Experiment 2, the temporal distribution of responding was examined for evidence of superpositioning.

In Experiment 2, conditioned responding was also assessed after extinction exposure to the experimental chambers, in the absence of CSs or USs. This manipulation was intended to reduce the contribution of any differences in contextual conditioning or pre-CS responding to performance differences across the groups. Furthermore, responding to the CSs was assessed in the absence of any USs in all the groups, providing another way of disentangling the effects of $I$ or the $I / T$ ratio on learning and performance. If the magnitude of conditioned responding reflects a comparison of the associative strengths or representations of food rate during $T$ and $I$ (see, e.g., Gibbon \& Balsam, 1981; Miller \& Matzel, 1988), pretest extinction of the context should produce equal $I$ values for all the groups, and testing should reveal differences in CS $(T)$ strength only.

Finally, Experiment 2 also used a blocking procedure to provide a measure of conditioning strength that might be relatively independent of the form or temporal distribution of responding controlled by the CSs in the various groups (Holland, 1977, 1980). At the end of training, a 10sec visual cue was presented during the final $10 \mathrm{sec}$ of the noise CS in each group and was followed by food delivery. Conditioned responding to the common visual CS alone was then assessed in all the groups. The stronger 
the conditioning of the noise (or the better it predicted food delivery), the less conditioning of the visual CS would be anticipated.

\section{Method}

Subjects. Thirty-two experimentally naive female CD-strain rats (bred in a Duke psychology department vivarium from Charles River stock), 4-5 months old at the beginning of the experiment, served as subjects. They were maintained in the same way as the rats in Experiment 1.

Apparatus. The apparatus was the same as that used in Experiment 1.

Procedure. Initially, all the rats were trained to eat from the recessed food cup. In a single 64-min session, there were 16 deliveries of the two-pellet US on a VT 2-min schedule. Next, all rats received eight pairings of the 80-dB white noise CS with the food US in each of 20 daily conditioning sessions. Each group of rats received a single combination of $T$ and $I$, as specified (in seconds) by the group name, $T-I: 20-120,40-240,80-480$, and 160-960. In each group, the noise CS remained on throughout $T$. The Is were variable, with the specified arithmetic mean; the values ranged from 0.5 to 1.5 times the mean, rectangularly distributed, as in Experiment 1 . The session lengths were eight times the mean $I$ values and so varied from 16 to $256 \mathrm{~min}$ across the groups.

Next, the rats received four context extinction sessions, designed to reduce context conditioning and base rate responding. The first two of these sessions were $128 \mathrm{~min}$ long, and the second two were $16 \mathrm{~min}$ long, in all the groups. Then the rats received two 64-min test sessions, in which eight noise CSs but no food pellets were delivered. In those sessions, the $T_{\mathrm{s}}$ in each group were those used in training, but $I$ was $480 \mathrm{sec}$ in all the groups.

After four retraining sessions identical to those of the original conditioning phase, the rats received four compound conditioning sessions. These sessions were identical to the retraining sessions, except that the jeweled lamp above the food cup was illuminated during the final $10 \mathrm{sec}$ of each noise presentation. Finally, conditioning to this light CS was assessed in a single 16-min test session in each group, which included four nonreinforced light presentations, with an average $I$ of $240 \mathrm{sec}$.

Data presentation. In Experiment 2, the only response measures reported were the percentage of time spent in the food cup during CS and pre-CS periods and the difference between those two values (elevation scores). As in Experiment 1, food cup entry rates and latencies were only minimally sensitive to the temporal variables after the early stages of training. Because Experiment 2 involved even more protracted training than did Experiment 1, food cup entry rates and latencies were not reported. Also, as in Experiment 1 , the focus was on responding during the final $10 \mathrm{sec}$ of the $\mathrm{CS}$ in each group. However, a more detailed analysis of the temporal distribution of responding is also presented.

\section{Results}

Acquisition. Higher levels of responding were acquired in groups with shorter values of $I$ and $T$, despite the common $I / T$ ratio. Figure 4 shows the percentages of time the rats spent in the food cup during the last $10 \mathrm{sec}$ of the CS and in the $10-\mathrm{sec}$ pre-CS periods and the difference between those two measures (elevation scores). Group $\times$ session block ANOVAs were conducted for each of the three measures. In each case, the group $\times$ session blocks interaction was reliable $\left[F_{\mathrm{s}}(21,196) \geq 1.72, p \mathrm{~s}<\right.$ $.05]$. Likewise, contrasts of the linear variation (over session blocks) in the linear trend across groups (as a function of $I$ and $T)$ were reliable in all cases $[F \mathrm{~s}(1,28) \geq 9.15$, $p \mathrm{~s}<.01]$. Thus, conditioned responding to the CS in-
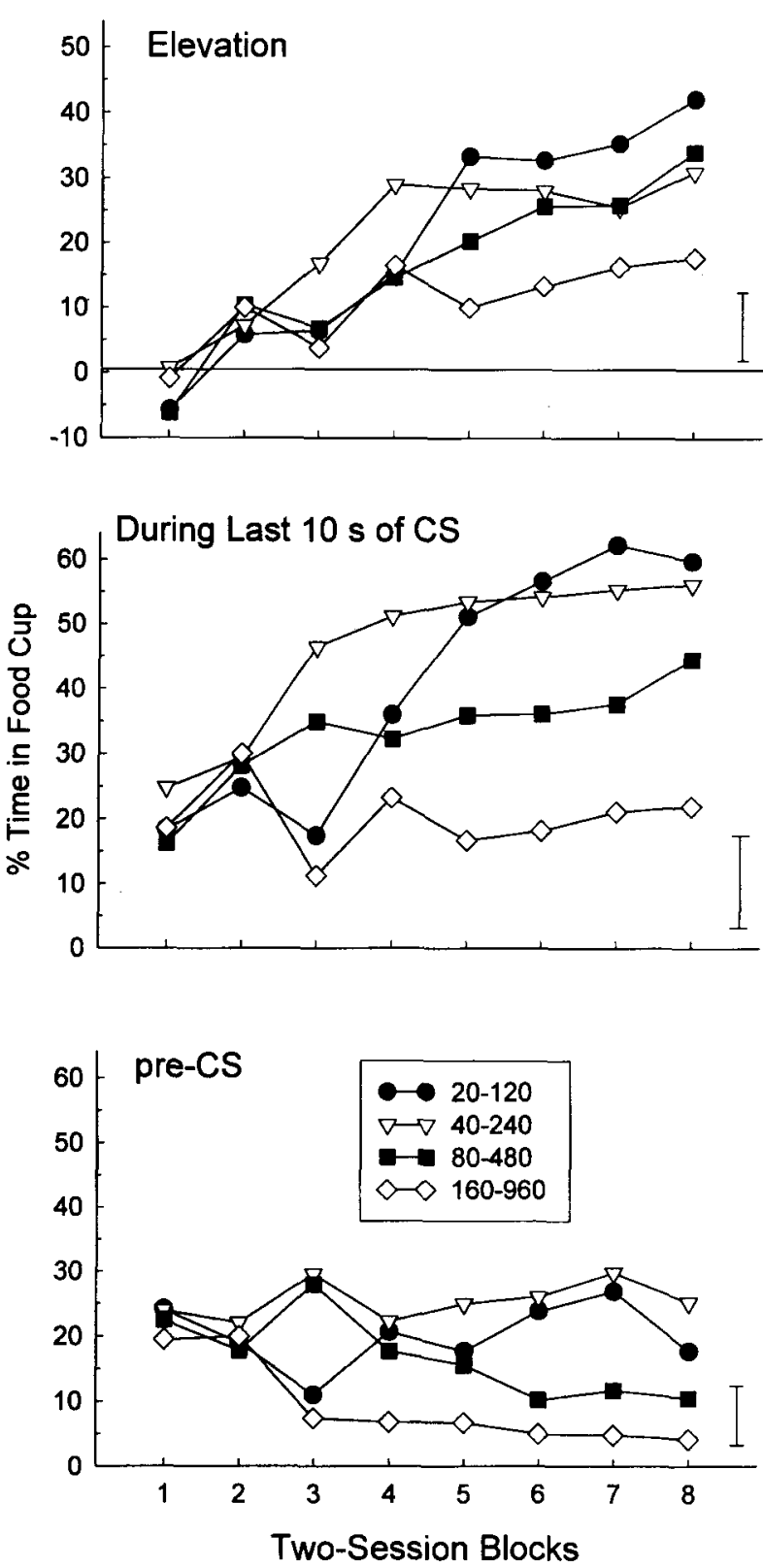

Figure 4. Acquisition of conditioned responding over sessions in Experiment 2. The first number in each group designation in the legend indicates the trial duration, and the second number signifies the intertrial duration, both in seconds. The top panels show elevation scores, calculated by subtracting responding during the 10-sec period immediately prior to conditioned stimulus (CS) presentation (bottom panel, Pre-CS) from responding during the last 10 sec of the CS (middle panel). The error bars in each panel show two times the pooled standard error of the betweengroups means.

creased more rapidly the shorter the $I$ (and $T$ ). Likewise, pre-CS responding among the groups diverged as training proceeded, with greater responding the shorter the $I$ (and $T$ ).

Finally, asymptotic responding was analyzed by conducting separate ANOVAs for the last half of training 
(Sessions 9-16). Those analyses all showed reliable effects of group $[F \mathrm{~S}(3,28) \geq 3.73, p \mathrm{~s}<.05]$ and no significant effects of session blocks or group $X$ session blocks interactions $(p s>.20)$. For the elevation scores, there was a decreasing linear trend across groups $[F(1,28)=10.34$, $p<.01]$. Post hoc comparisons (Duncan's test) showed only that responding in Group 160-960 was reliably ( $p<$ .05 ) less than that in Groups $20-120$ and 40-240. For responding during the last $10 \mathrm{sec}$ of the $\mathrm{CS}$, there was also a decreasing linear trend across groups $[F(1,28)=34.27$, $p<.01]$. Duncan's tests showed the differences in responding between each pair of groups to be reliable $(p<$ .05 ), except for that between Groups 20-120 and 40-240.

Pre-CS responding also showed a decreasing linear trend across groups $[F(1,28)=25.69, p<.01]$. Duncan's tests showed that Groups 20-120 and 40-240 each differed from each of Groups 80-480 and 160-960 ( $p$ s $<.05)$.

Temporal distribution of responding in acquisition. By the end of training, the rats in all the groups showed gradually increasing response levels over the course of $T$. The left panel of Figure 5 shows elevation scores over the final four sessions of acquisition, divided into $10-\mathrm{sec}$ bins. The right panel of Figure 5 shows responding from the same sessions, normalized over quarters of $T$ in each group by dividing the time spent in the food cup during each quarter of $T$ by the total time spent in the food cup during the entire $T$. Superpositioning was evident: The slopes of the normalized $T$ functions among the groups were indistinguishable. The extent of superpositioning was evaluated by conducting a group $\times$ quarter (of $T$ ) ANOVA of the normalized elevation scores. The lack of a significant group $\times T$ quarter interaction $[F(9,84)=1.27, p>.20]$, coupled with a reliable effect of $T$ quarter $[F(3,28)=$ $54.94, p<.01]$, demonstrates the extent of the superpositioning. Decomposition of the $T$ quarter effect into orthogonal polynomials showed reliable linear and quadratic trends $[F \mathrm{~s}(1,28)=73.58$ and $15.86, p \mathrm{~s}<.01]$.

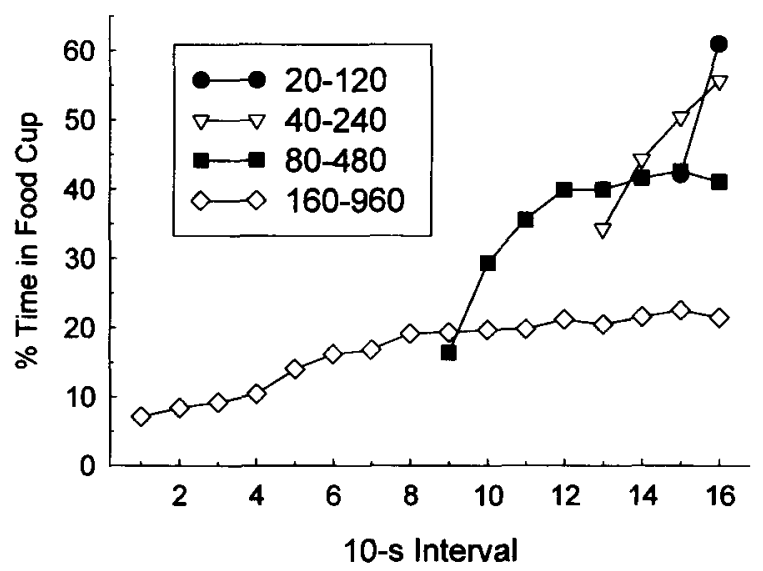

Figure 6 shows the change in the temporal distribution of elevation scores over successive quarters of the acquisition training sessions. Unfortunately, the time bins used early in training permitted only normalizing the data by halves of $T$ in this figure. Prior to the display of greater responding during the $\mathrm{CS}$ than in the pre-CS periods (first quarter of training; compare with Figure 4), responding was evenly distributed across $T$. However, as soon as positive elevation scores emerged (second quarter of training), that responding showed substantial temporal specificity.

Extinction test responding. After training, all the rats received four context extinction sessions in the experimental chambers in the absence of any explicit events, in an attempt to equalize the levels of pre-CS responding among the four groups. Then, responding to the CSs was reassessed in two extinction test sessions. In that test, the highest elevation scores were observed in Group 40-240, the lowest in Group 160-960, and intermediate levels in the other two groups.

Figure 7 shows elevation scores over the four halfsession blocks of testing. A group $\times$ blocks ANOVA showed a reliable effect of groups $[F(3,28)=3.40, p<$ $.05]$. Both linear and quadratic trends across groups were reliable $[F \mathrm{~s}(1,28)=5.56$ and $4.19, p \mathrm{~s}<.05]$, although only the comparison of Group 40-240 and Group 160 960 was reliable $(p<.05)$ by a Duncan's test. Comparable analyses of responding during the CSs showed the same pattern, but with larger $F$ values. The levels of preCS responding did not differ among the groups (range, $5.3 \%-8.8 \% ; F<1$ ), which indicates that the context extinction phase was successful.

Figure 8 shows the normalized temporal distribution of responding over the course of the extinction test phase. A group $\times$ quarter (of $T$ ) $\times$ block of extinction trials ANOVA of the normalized elevation scores showed a reliable effect of $T$ quarter $[F(3,28)=25.13, p<.01]$, but no other significant effects or interactions $(p s>.20)$.

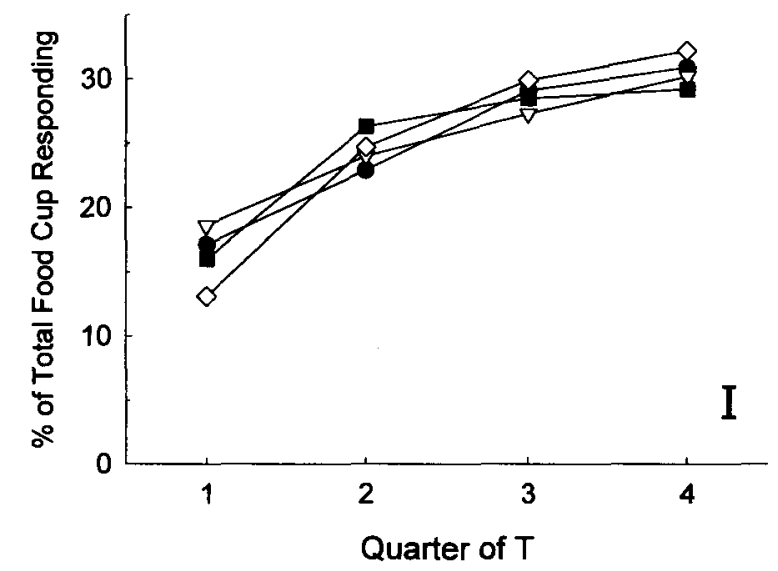

Figure 5. Temporal distribution of responding in the last four-session block of acquisition in Experiment 2. The first number in each group designation in the legend indicates the trial duration $(T)$, and the second number signifies the intertrial duration, both in seconds. The left panel shows responding during presentations of the conditioned stimulus as a function of 10 -sec bins of $T$. The right panel shows that same performance, normalized across quarters of $T$ by dividing the time spent in the food cup during each quarter of $T$ by the total time spent in the food cup during the entire $T$. The error bar shows two times the pooled standard error of the within-groups means. 


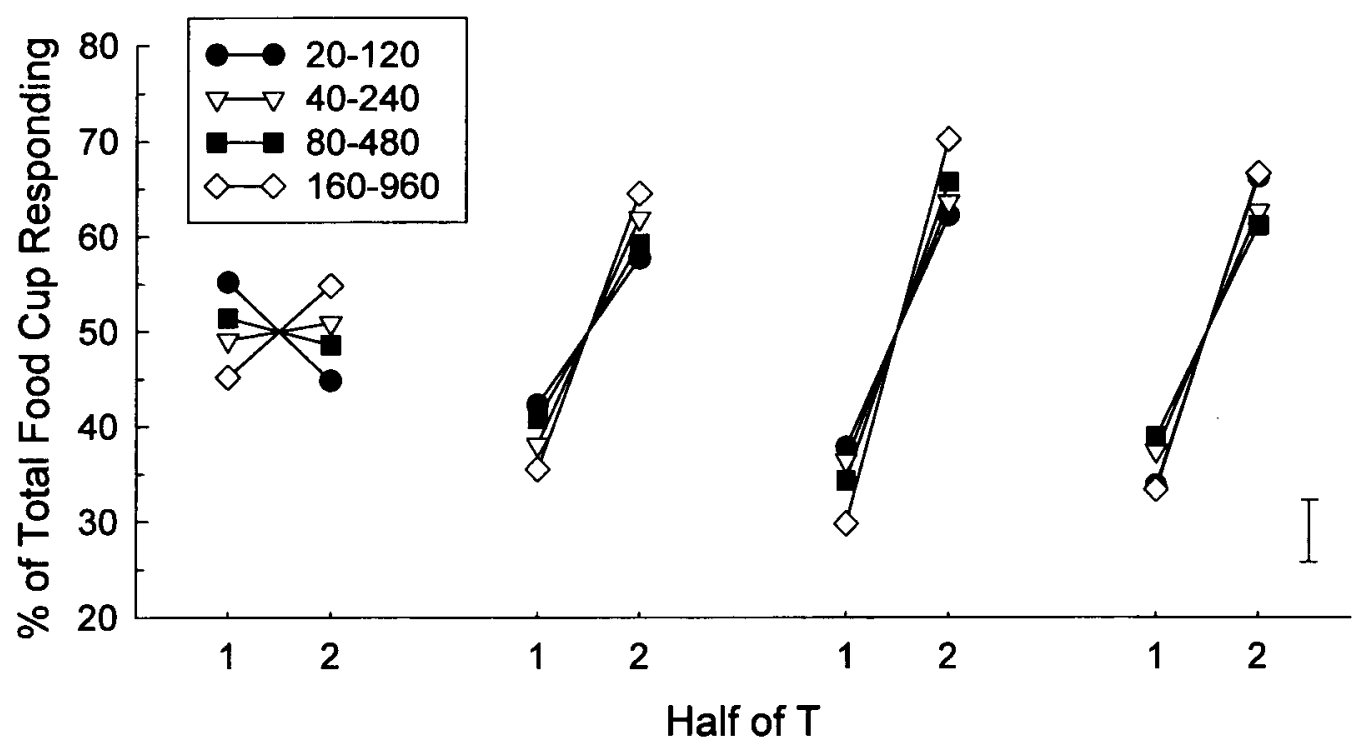

Four-Session Block

Figure 6. Change in temporal distribution of responding in the acquisition phase of Experiment 2. The first number in each group designation in the legend indicates the trial duration $(T)$, and the second number signifies the intertrial duration, both in seconds. In each four-session block, performance in each group was normalized across halves of $T$ by dividing the time spent in the food cup during each half of $T$ by the total time spent in the food cup during the entire $T$. The error bar shows two times the pooled standard error of the within-groups means.

Thus, the temporal distribution of responding was maintained as its level declined.

Blocking (light) test. Figure 9 shows the elevation scores for the light CS during the blocking test. The elevation scores of the four groups of rats in this test were inversely related to the elevation scores in those groups in the extinction test with the noise CS (Figure 7). This finding is consistent with the claim that variations in responding to the light in the blocking test reflected variations in the ability of the noise CS to block the establishment of new learning. A one-way ANOVA showed a reliable effect of groups $[F(3,28)=9.40, p<.01]$; multiple comparisons using Duncan's procedure showed that the responding of Group 40-240 was lower than that of each of the other groups and that the responding of Group 160-960 was higher than that of each of the other groups $(p s<.05)$. Responding during the CS alone exhibited a similar pattern, and pre-CS responding did not differ among the groups $(F<1)$. Finally, the correlation between responding to the light in the blocking test and to the noise in the extinction test among the individual rats (in all groups combined) was -.74.

\section{Discussion}

Despite a common $I / T$ ratio, the rates of acquisition and the final levels of conditioned responding differed across groups. In the acquisition phase, those rats trained with shorter Is and Ts showed higher elevation scores and more responding during both $\mathrm{CS}$ and pre-CS periods than did the rats trained with longer $I \mathrm{~s}$ and $T \mathrm{~s}$. After elimination of the differential pre-CS rates by context extinction, the greatest elevation scores and CS responding were observed in those rats that received $40-\mathrm{sec} T \mathrm{~s}$ and 240 $\mathrm{sec} I \mathrm{~s}$. These intervals also generated the most interference with conditioning of the $10-\mathrm{sec}$ light when it was compounded with the noise. Although the absence of controls for conditioning of the noise CSs prior to the compound conditioning phase precluded the identification of the variations in responding to the light as the result of differences in blocking rather than in overshadowing, the implications of either are similar. All in all, the results of Experiment 2 show that, with very long intervals, the absolute values of $I$ or $T$ can be important beyond their contribution to the $I / T$ ratio.

Previous studies with this conditioning preparation also showed that 240-sec Is supported better learning than did shorter Is (e.g., Holland, 1995, 1999; Holland \& Morell, 1996), although those same studies showed that 480 -sec Is supported either equivalent (Holland, 1995) or superior (Holland \& Morell, 1996) learning. It is possible that the relation observed in Experiment 2 reflects a tradeoff between independent facilitatory effects of longer Is and shorter $T \mathrm{~s}$. On the other hand, it might be argued that $T$ alone determined variations in learning among the groups and that the greater responding of Group 40-240, as compared with Group 20-120, in the postextinction and 

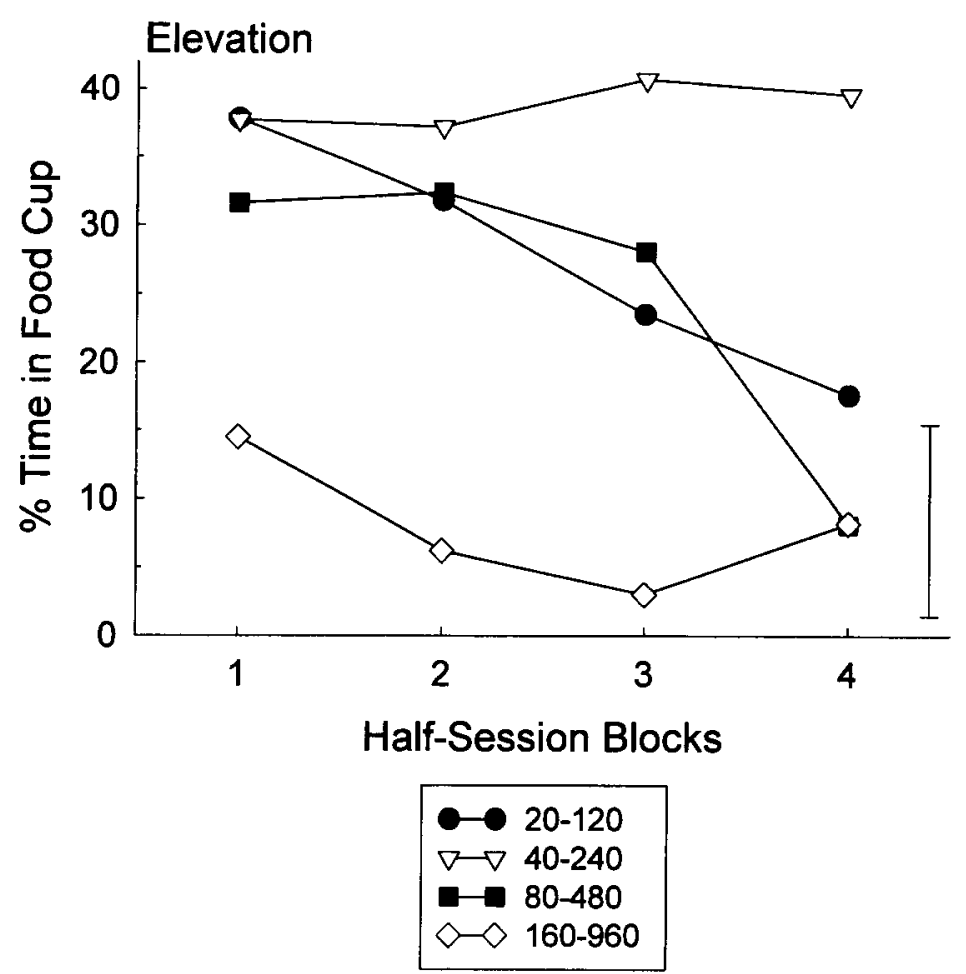

Figure 7. Responding over the course of the extinction test of Experiment 2. The first number in each group designation in the legend indicates the trial duration, and the second number signifies the intertrial duration, both in seconds. The response measure shown is the elevation score, calculated by subtracting responding during the 10-sec period immediately prior to conditioned stimulus (CS) presentation from responding during the last 10 sec of the CS. The error bar shows two times the pooled standard error of the betweengroups means.

blocking tests reflected greater generalization decrement from the training procedures in the latter group. Note that in the extinction test, $I$ was $480 \mathrm{sec}$ in all the groups, and in the blocking test, it was $240 \mathrm{sec}$ in all the groups. However, this account seems less plausible, given that, in Experiment 1, interval effects established in the conditioning phase persisted in the performance test, in which $I$ was shifted in most groups.

Perhaps the most striking result of Experiment 2 was the evidence for response timing. In all the groups, responding increased over the course of $T$ and showed a maximum nearest the time of food delivery. Furthermore, consistent with scalar timing, when they were normalized across quadrants of the ISI, the response distribution functions were identical in all groups (superpositioning). This distribution of behavior was not present at the beginning of training but was observed from the time that CRs were first exhibited and throughout extinction.

\section{GENERAL DISCUSSION}

These results add to the evidence for the importance of timing processes in Pavlovian conditioning procedures. First, the $I / T$ ratio played a key role in determining the acquisition and maintenance of conditioned responding in this conditioning preparation, supporting the previous research of Gibbon et al. (1977), Lattal (1999), and others. Second, the distribution of responding within $T$ showed several features consistent with the predictions of scalar timing theories, derived in quite different circumstances (Gibbon, 1977).

In Experiment 1, the $I / T$ ratio was a better predictor of acquisition and terminal performance than were the six values of $I$ or the two values of $T$, considered separately. Nevertheless, in Experiment 2, the I/T ratio's predictive power broke down as the intervals were lengthened. Thus, with long intervals, the absolute values of $I$ and/or $T$ may contribute separately to responding, in addition to their roles in determining the $I / T$ ratio. Without a more complete exploration of the $I / T$ space, it is premature to attempt to construct or evaluate quantitative models of the contributions of these temporal variables in this conditioning preparation (see, e.g., Buhusi \& Schmajuk, 1999). Perhaps more important is the increasing recognition that relative timing is widespread in conditioning.

Although there are many accounts for the origins of both trial-spacing effects (e.g., Ewing, Larew, \& Wagner, 1985; Papini \& Brewer, 1994; Solomon \& Corbit, 1974) and ISI functions (e.g., Mackintosh, 1983) in Pavlovian conditioning, there are surprisingly few that read- 


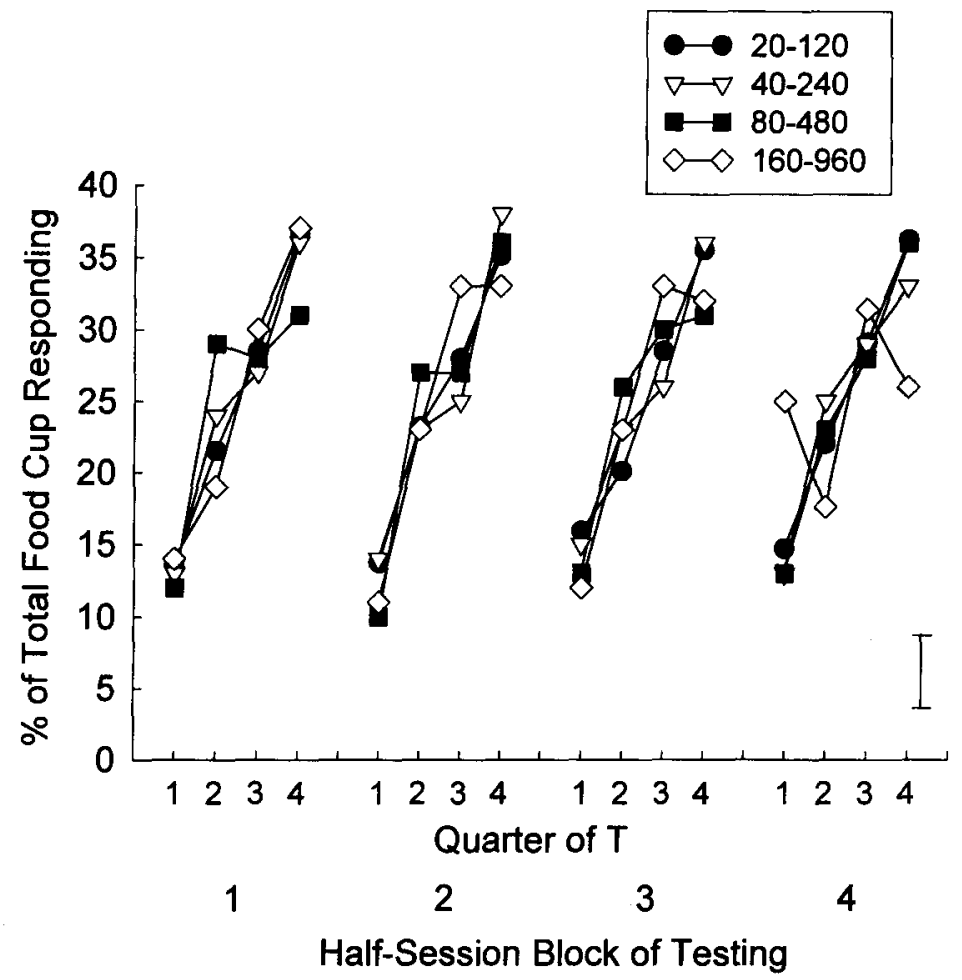

Figure 8. Change in temporal distribution over the course of the extinction test in Experiment 2. The first number in each group designation in the legend indicates the trial duration $(T)$, and the second number signifies the intertrial duration, both in seconds. In each half-session block, performance in each group was normalized across quarters of $T$ by dividing the time spent in the food cup during each quarter of $T$ by the total time spent in the food cup during the entire $T$. The error bar shows two times the pooled standard error of the within-groups means.

ily encompass observations of the importance of the ratio of those intervals across a broad range of time intervals. Casual suggestions include the possibility that animals may use $I$ as a temporal context in which the $T$ is evaluated (Spetch \& Rusak, 1989), that they may use $T$ as a temporal context to evaluate $I$ (Gibbon et al., 1977), and that Gestalt grouping principles are involved (Holland, 1995).

The best-known approach to animals' use of relative time intervals in conditioning is Gibbon and Balsam's (1981) adaptation of scalar expectancy theory (Gibbon, 1977). They proposed that animals independently acquire expectancies of the reinforcer during the CS and in the experimental context in general. These expectancies are sensitive to the delays to reinforcement during the CS $(T)$ and in the context as a whole $(I)$; the shorter the delay, the greater the expectancy. The strength of conditioned responding evoked by the CS is then determined by a ratio comparator, which takes a ratio of the strengths of expectancy during the $\mathrm{CS}$ and context. Both the basic effects of $I$ and $T$ and the effects of the $I / T$ ratio are easily derived from these assumptions. The shorter the $I$, the greater the context strength and, hence, the smaller the ratio of CS to context strength. Thus, with any single $T$, there will be less responding with shorter Is (massed practice) than with with longer Is (spaced practice). Likewise, with any value of $I$, the shorter the $T$, the greater the CS strength and, hence, the greater the $I / T$ ratio. Finally, because it is the ratio of CS and context expectancies that determine responding, any combination of $I$ and $T$ that yields the same ratio should generate the same amount of responding.

Gibbon and Balsam (1981) and Gibbon et al. (1977) noted that this ratio invariance of conditioning demands immediate abstraction of the average delay to reinforcement in the context - that is, rapid contextual learning. In support of that claim, Balsam and Schwartz (1981) found rapid contextual learning in an autoshaping situation. In Gibbon and Balsam's (pp. 236-241, 249-251) derivations, if contextual learning is relatively slow, the absolute value of $I$ may also contribute to the emergence of conditioned responding, especially when, as in the present experiments, CS-US pairings are preceded by food cup training with relatively short Is. Briefly, if contextual learning is slow, the higher intertrial reinforcement expectancies established in preliminary food cup training will reduce the ratio of trial and intertrial expectancies at the outset of the explicit conditioning phase. The 


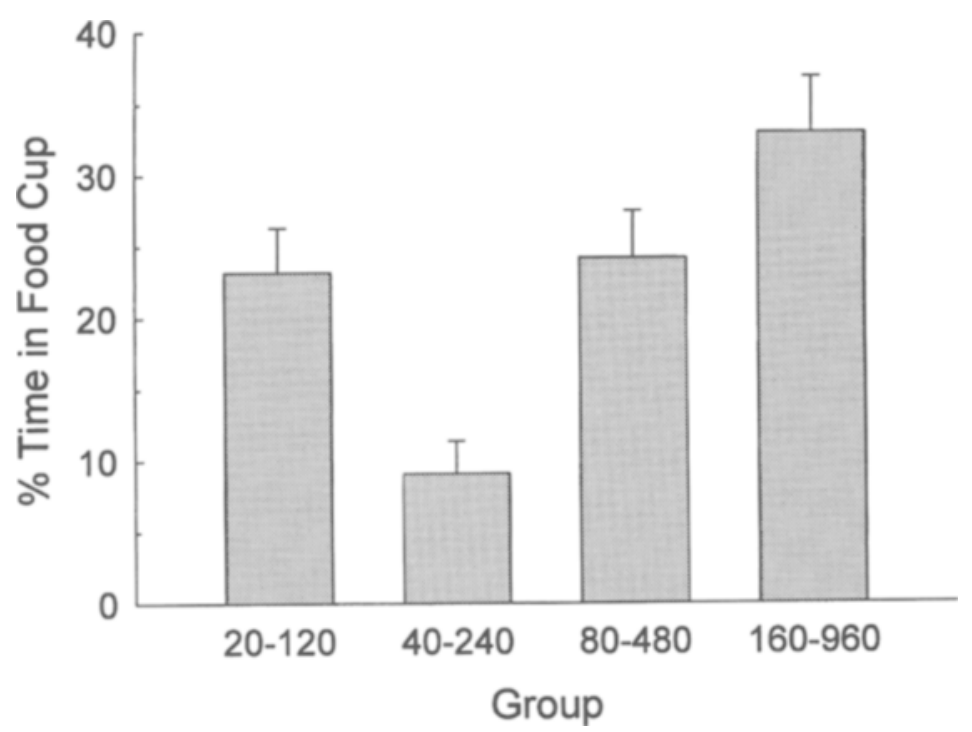

Figure 9. Conditioned responding during the light conditioned stimulus (CS) in the blocking test of Experiment 2. The first number in each group designation indicates the trial duration, and the second number signifies the intertrial duration, both in seconds. The response measure shown is the elevation score, calculated by subtracting responding during the 10 -sec period immediately prior to CS presentation from responding during the last $10 \mathrm{sec}$ of the CS. The error bars show the standard errors of the means.

greater the value of $I$ in the conditioning phase, the proportionally greater this reduction and, hence, the more retarded the acquisition of responding. Thus, the apparent effects of $I$ beyond those of the $I / T$ ratio found in Experiment 2 may reflect slower contextual learning than occurred in studies from other laboratories. Although it is difficult to compare the rate of contextual learning in this laboratory with that found in other laboratories, two observations are noteworthy. First, in both experiments in this article, emergence of between-groups differences in pre-CS responding was gradual. Second, an attempt within a network model (Schmajuk, Lamoureux, \& Holland, 1998) to simulate differences in the transfer of occasion setting found in this laboratory compared with others suggested that contextual learning might be unusually slow here.

The simplest version of Gibbon and Balsam's (1981) account for ratio effects in conditioning invokes the ratio comparison at the time of performance. That is, the intertrial and trial expectancies are separately acquired and stored and are only compared at the instant of action (see Miller \& Matzel, 1988, for examples of data that support this claim in the framework of comparator theory, which makes a similar performance assumption to account for broader aspects of contingency learning). An implication of this assumption is that posttraining alteration of the intertrial expectancy should have large effects on subsequently assessed responding to the CS in that context. For example, extended exposure to the context without US presentations should reduce the intertial expectancy value and, hence, should enhance responding to the CS. Likewise, changes in the rate of US presentation $(I)$ after training should result in rapid adjustments to the intertrial expectancy and, hence, appropriate increases or decreases in responding to CSs. Interestingly, changes like these did not occur in the experiments reported here. In Experiment 1 , all the groups received test sessions with two $I$ values, which in training produced very different response levels. Performance of each group was similar at both values of $I$ and was similar to its performance with its original $I$ in training. Likewise, in Experiment 2, although exposure to the context in the absence of the US reduced responding to the context alone, it had little effect on subsequent responding during the CSs. Furthermore, between-groups differences in responding to the CS persisted throughout extinction test sessions in which no USs were presented. Thus, it seems reasonable to conclude either that the ratio comparison affects learning itself or that, at least in this preparation, the intertrial expectancy, once established, is resistant to change.

Considerable evidence for timing of food cup responding within $T$ was observed in Experiment 2. Consistent with claims that the time of US delivery is an important feature of conditioning episodes coded in associative learning (e.g., the temporal coding hypothesis; Miller \& Barnet, 1993), responding increased throughout the CSUS interval $(T)$, showing a maximum at the time of US delivery. Furthermore, the distribution of responding across $T$ was proportional across a wide range of temporal intervals, showing superpositioning. Like the trial ratio effect, this finding is consistent with scalar expectancy theory; indeed, superpositioning of relative response distributions over different ranges of absolute time is often considered the hallmark of scalar timing (Gib- 
bon, 1977). The observation that both the timing and the superimposition emerged early in training and persisted unchanged throughout training and extinction in Experiment 2 supports the claim that associative strength and temporal information are separately represented (Brown \& Hemmes, 1997; Miller \& Barnet, 1993). Furthermore, these findings make it tempting to link all of the features of timing found here. However, data from other preparations show that it is unlikely that these aspects of timing depend crucially on one another. For example, Gibbon et al. (1977) found no evidence of within- $T$ response timing until long after subjects showed sensitivity to the $I / T$ ratio in reaching an acquisition criterion. Likewise, Ohyama, Gibbon, Deich, and Balsam (1999) found superpositioning of relative response distributions, but the peak rate of responding was reached early in $T$, rather than near the time of US delivery.

The observation of temporally distributed responding has implications for comparisons of the associative strengths of CSs with different temporal parameters. The observation of superpositioning, as in Experiment 2, suggests that the most appropriate comparison of response levels is across equal proportions of the CS. In this light, it is worth revisiting the use of the final 10 -sec CS period in these experiments, which was intended to provide an equal sampling interval and to capture the maximum expectancy, just before US delivery, in all conditions. First, given superpositioning and the relatively flat responding observed over the last half of each interval, it is not surprising that, in Experiment 2, the use of a constant 10 -sec sampling interval and responding averaged over any given proportion of $T$ (e.g., the whole $\mathrm{CS}$, the last half) yielded very similar results, as can be inferred from Figure 5.

Second, the comparison of responding during the last 10 -sec interval of both 10-sec and 20-sec Ts in Experiment 1 may also seem inappropriate. It could be argued that a better procedure would have been to compare responding during the entire CS in both conditions. When the data of Experiment 1 were analyzed in this manner, the results were similar to those found with the 10 -sec sample, except that the overall levels of responding in the 20 -sec $T$ conditions were somewhat lower. Although an ANOVA and a regression analysis conducted with the whole-CS data again showed a reliable effect of $I / T$ ratio, and not of $T$-alone, in these analyses the $I / T$ ratio accounted for a smaller proportion of the variance than when the data from the last 10 -sec interval were considered. On the other hand, it is worth noting that previous studies (Holland, 1977, 1980) showed a relatively flat distribution of food-related behaviors across the first and last 5-sec periods of 10-sec noise CSs in experiments similar to these. Thus, it might be argued that the 10-sec sample used was a good estimate of behavior in the last half of $T$ in both the 10-sec and the 20-sec conditions in Experiment 1 . Furthermore, the relatively flat distributions of responding found within both 10-sec and 5-sec CSs in this conditioning preparation (Holland, 1980) suggest lim- its to superpositioning in this context and call into question the appropriateness of comparing behavior across equal proportions of 20-sec intervals, which show a clear temporal gradient of responding, and 10-sec CSs, which apparently do not. Should comparisons be of average responding across different $T \mathrm{~s}$ or of maximal responding, nearest the time of US delivery? In the absence of superpositioning, these two comparisons are not equivalent.

Given graded temporal distributions of responding, the implications of blocking and other indirect assessments of associative strength conditioning also need to be considered carefully. Although measuring the ability of one stimulus to block conditioning of another stimulus is often regarded as a powerful alternate method for evaluating the associative strength of the first stimulus (Rescorla \& Holland, 1976), it is unlikely that blocking is immune to temporal distribution effects (see Barnet, Grahame, \& Miller, 1993, for evidence of the importance of timing in blocking). For example, in Experiment 2, the light stimulus was added during the last $10 \mathrm{sec}$ of the noise CSs, closest to the time of food delivery. If estimates of the time of US delivery provided by the noise CSs in the various groups were scalar, then the longer the $T$, the less accurate the prediction of the time of US delivery and, hence, the less blocking. Thus, the results of the blocking test of Experiment 2 would be anticipated on the basis of either differences in associative strength or differences in timing. A similar argument could be made in the case of other indirect assessments of associative strength, such as a CS's ability to support second-order conditioning (see, e.g., Barnet, Cole, \& Miller, 1997; Brown \& Hemmes, 1997; Holland, 1977, 1980).

An adequate theory of associative learning must be able to characterize a number of timing phenomena within conditioning, including those described here. The task is made difficult by the variety of data available. Different behavior systems may show optimal conditioning with different CS durations or CS-US intervals, even within the same experiment (e.g., Holland, 1980; Silva \& Timberlake, 1997). Likewise, the temporal distribution of responding during the CS differs dramatically across responses, sometimes peaking near the beginning of a CS (e.g., Holland, 1980; Ohyama et al., 1999), sometimes near the end (e.g., Brown \& Hemmes, 1997; Holland, 1980), and sometimes at intermediate times (e.g., Holland, 1980; Levey \& Martin, 1968; Smith, 1968). Furthermore, although conventional wisdom and much data support the claim that spaced practice is superior to massed practice, sometimes $I$ effects are not found (e.g., Carrillo, Thompson, Gabrieli, \& Disterhoft, 1997), and in some discrimination tasks, massed practice has been found to generate superior performance (e.g., Honey, 1996). Finally, ratio sensitivity may not be universal. For example, although Williams (1998) found that the effects of $I$ interacted with those of the interval between the presentation of a discriminative stimulus and the time of response availability, they did not interact with the effects of the interval introduced between response and reinforcer. 
Theories of timing in conditioning may profit from further exploration of the boundary conditions for the observation of effects of $I, T$, and the $I / T$ ratio.

\section{REFERENCES}

Balsam, P. D., \& SchwarTz, A. L. (1981). Rapid contextual conditioning in autoshaping. Journal of Experimental Psychology, 7, 382-393.

Barnet, R. C., Cole, R. P., \& Miller, R. R. (1997). Temporal integration in second-order conditioning and sensory preconditioning. Animal Learning \& Behavior, 25, 221-233.

Barnet, R. C., Grahame, N. J., \& Miller, R. R. (1993). Temporal encoding as a determinant of blocking. Journal of Experimental Psychology: Animal Behavior Processes, 19, 327-341.

Brown, B. L., \& Hemmes, N. S. (1997). Timing of the CS-US interval by pigeons in trace and delay autoshaping. Quarterly Journal of Experimental Psychology, 50B, 40-53.

Buhusi, C. V., \& SchmajuK, N. A. (1999). Timing in simple conditioning and occasion setting: A neural network approach. Behavioural Processes, 45, 33-57.

CAPALDI, E. J. (1967). A sequential hypothesis of instrumental learning. In K. W. Spence \& J. T. Spence (Eds.), The psychology of learning and motivation (Vol. 1, pp. 67-156). New York: Academic Press.

Carrillo, M. C., Thompson, L. T., Gabrieli, J. D. E., \& Disterhoft, J. F. (1997). Variation of the intertrial interval in human classical conditioning. Psychobiology, 25, 152-157.

Catania, A. C. (1970). Reinforcement schedules and psychophysical judgments. In W. N. Schoenfeld (Ed.), The theory of reinforcement schedules (pp. 1-42). New York: Appleton-Century-Crofts.

Ewing, M. F., Larew, M. B., \& WaGner, A. R. (1985). Distributionof-trials effects in Pavlovian conditioning: An apparent involvement of inhibitory backward conditioning with short intertrial intervals. Journal of Experimental Psychology: Animal Behavior Processes, $11,537-547$.

GALlistel, C. R. (1990). The organization of learning. Cambridge, MA: MIT Press.

GibBon, J. (1977). Scalar expectancy theory and Weber's law in animal timing. Psychological Review, 84, 279-325.

Gibbon, J., Baldock, M. D., Locurto, C. M., Gold, L., \& Terrace, H. S. (1977). Trial and intertrial durations in autoshaping. Journal of Experimental Psychology: Animal Behavior Processes, 3, 264-284.

GibBON, J., \& BalsaM, P. (1981). Spreading association in time. In C. M. Locurto, H. S. Terrace, \& J. Gibbon (Eds.), Autoshaping and conditioning theory (pp. 219-253). New York: Academic Press.

Gibbon, J., \& Church, R. M. (1990). Representation of time. Cognition, 37, 23-54

Grau, J. W., \& Rescorla, R. A. (1984). The role of context in autoshaping. Journal of Experimental Psychology: Animal Behavior Processes, 10, 324-332.

Holland, P. C. (1977). Conditioned stimulus as a determinant of the form of the Pavlovian conditioned response. Journal of Experimental Psychology: Animal Behavior Processes, 3, 77-104.

Holland, P. C. (1980). CS-US interval as a determinant of the form of Pavlovian appetitive conditioned responses. Journal of Experimental Psychology: Animal Behavior Processes, 6, 155-174.

Holland, P. C. (1995). The effects of intertrial and feature-target intervals on operant serial feature-positive discrimination learning. $\mathrm{An}$ imal Learning \& Behavior, 23, 411-428.

Holland, P. C. (1999). Intertrial interval effects in Pavlovian serial feature positive discriminations. Animal Learning \& Behavior, 27, 127 139.

Holland, P. C., Lamoureux, J. A., Han, J.-S., \& Gallagher, M. (1999). Hippocampal lesions interfere with negative occasion setting. Hippocampus, 9, 143-157.

Holland, P. C., \& Morell, J. M. (1996). The effects of feature-target and intertrial intervals (ITI) on learning and performance of serial feature negative discriminations. Learning \& Motivation, 27, 21-42.

HONEY, R. C. (1996). The temporal dynamics of a visual discrimination: The role of stimulus comparison and opponent processes. Journal of Experimental Psychology: Animal Behavior Processes, 22, 461-471.
Kamin, L. J. (1965). Temporal and intensity characteristics of the conditioned stimulus. In W. F. Prokasy (Ed.), Classical conditioning: $A$ symposium (pp. 118-147). New York: Appleton-Century-Crofts.

KILLEEN, P. (1975). On the temporal control of behavior. Psychological Review, 82, 89-115.

LATTAL, K. M. (1999). Trial and intertrial durations in Pavlovian conditioning: Issues of learning and performance. Journal of Experimental Psychology: Animal Behavior Processes, 25, 433-450.

LEveY, A. B., \& Martin, I. (1968). Shape of the conditioned eyelid response. Psychological Review, 75, 398-408.

MaCKInTosh, N. J. (1983). Conditioning and associative learning. Oxford: Oxford University Press, Clarendon Press.

Miller, R. R., \& BARNET, R. C. (1993). The role of time in elementary associations. Current Directions in Psychological Science, 2, 106-111.

Miller, R. R., \& MAtzel, L. D. (1988). The comparator hypothesis: A response rule for the expression of associations. In G. H. Bower (Ed.), The psychology of learning and motivation (Vol. 22, pp. 5192). San Diego: Academic Press.

Ohyama, T., Gibbon, J., Deich, J. D., \& Balsam, P. D. (1999). Temporal control during maintenance and extinction of conditioned keypecking in ring doves. Animal Learning \& Behavior, 27, 89-98.

PAPINI, M. R., \& Brewer, M. (1994). Response competition and the trial spacing effect in autoshaping with rats. Learning \& Motivation, 25, 201-215.

Rescorla, R. A., \& Holland, P. C. (1976). Some behavioral approaches to the study of learning. In E. Bennett \& M. R. Rozensweig (Eds.), Neural mechanisms of learning and memory (pp. 165-192). Cambridge, MA: MIT Press.

Rescorla, R. A., \& Wagner, A. R. (1972). A theory of Pavlovian conditioning: Variations in the effectiveness of reinforcement and nonreinforcement. In A. H. Black \& W. F. Prokasy (Eds.), Classical conditioning $I I$ (pp. 64-99). New York: Appleton-Century-Crofts.

RoberTs, W. A., \& Kraemer, P. J. (1982). Some observations of the effects of intertrial interval and delay on delayed matching to sample in pigeons. Journal of Experimental Psychology, 8, 342-353.

Ross, L. E. (1961). Conditioned fear as a function of CS-UCS and probe stimulus intervals. Journal of Experimental Psychology, 61, 265-273.

Savastano, H. I., \& Miller, R. R. (1998). Time as content in Pavlovian conditioning. Behavioural Processes, 44, 147-162.

Schmajuk, N. A., Lamoureux, J. A., \& Holland, P. C. (1998). Occasion setting: A neural network approach. Psychological Review, 105, 3-32.

Schneiderman, N., \& Gormezano, I. (1964). Conditioning of the nictitating membrane of the rabbit as a function of CS-US interval. Journal of Comparative \& Physiological Psychology, 57, 188-195.

Silva, K. M., \& TimberLake, W. (1997). A behavior systems view of conditioned states during long and short CS-US intervals. Learning \& Motivation, 29, 465-490.

SмIтн, M. C. (1968). CS-US interval and US intensity in classical conditioning of the rabbit's nictitating membrane response. Journal of Comparative \& Physiological Psychology, 66, 679-687.

Solomon, R. L., \& CoRBiT, J. D. (1974). An opponent-process theory of motivation: I. Temporal dynamics of affect. Psychological Review, 81, 119-145.

SPETCH, M. L., \& RuSAK, B. (1989). Pigeons' memory for event duration: Intertrial interval and delay effects. Animal Learning \& Behavior, 17, 147-156.

SPETCH, M. L., \& RuSAK, B. (1992). Temporal context effects in pigeons' memory for event duration. Learning \& Motivation, 23, 117 144.

WAGNER, A. R. (1981). SOP: A model of automatic memory processing in animal behavior. In N. E. Spear \& R. R. Miller (Eds.), Information processing in animals: Memory mechanisms (pp. 5-47). Hillsdale, NJ: Erlbaum.

Williams, B. A. (1998). Relative time and delay of reinforcement. Learning \& Motivation, 29, 236-248.

(Manuscript received August 23, 1999; revision accepted for publication December 13, 1999.) 